\section{Dispute over monitoring}

\section{London}

A DISPUTE broke out in the United Kingdom last week over responsibility for monitoring the release of genetically engineered organisms into the environment. The British government proposed recently that a new body should be responsible for environmental safety. But the Health and Safety Executive Executive (HSE), which has the responsibility now, and the Confederation of British Industry (CBI), criticized the government's plan.

The HSE's Advisory Committee on Genetic Manipulation (ACGM) bases its decisions on releases on legislation in the Health and Safety at Work Act, but its remit does not stretch to ensuring environmental safety. The Department of the Environment, in a green paper (consultative document) outlining legislation for this autumn's 'Green Bill', revealed plans to plug this gap with a new body. And this week the HSE agreed that "the absence of legal powers in the area of environmental safety must be addressed". But it warns against splitting the regulatory system between environment and the workplace and recommends the formation of a new committee under the auspices of the ACGM to advise the HSE and ministers on release proposals.

Brian Richards, chairman of the CBI's Biotechnology Working Party, also said a new body would be a mistake. "The ACGM has been doing a good job for years, and should be allowed to continue its work, strengthened to cover environmental issues", he said. "There is too much at stake to risk the introduction of sub-standard regulations." The Royal Commission on Environmental Pollution (RCEP) also recommended that the ACGM should be constituted in its own right to advise the Secretary of State for the Environment and the HSE on each proposed release. In a report that took three years to complete, the RCEP praised the committee and suggested it should also produce a code of practice, advise on the need for research and the possibility of categorizing new releases, and produce an annual report. The HSE also called for further discussion of the definition of genetic manipulation, the balance between protection of commercial confidentiality and public information and controls on products consisting of genetically manipulated organisms.

The Department of the Environment said the alternative proposals would be considered before the bill goes before parliament. The criticisms of the government proposals coincide with the announcement by the Department of Trade and Industry of a $£ 1.3$ million, three-year research programme into the "fate" of genetically manipulated organisms in the environment. The programme, called Prosamo (Planned Release of Selected and Modified Organisms), will investigate "new methods for detecting the spread and survival of very low numbers of modified organisms so that the results of releasing new products into complex natural environments can be assessed more accurately".

Ben Webb

\title{
Call for grant applications
}

Tokyo

JAPAN last week launched its long-awaited Human Frontier Science Program with a call for applications for grants, fellowships and subsidies for international workshops (see page 17 of 'Classified' in Nature of $\mathbf{3 1}$ August).

Twenty three-year grants worth about $\$ 500,000$ a year will be awarded to international teams of scientists led by principal researchers from one of the seven 'summit' nations or non-summit European Community nations for research on the brain and biological functions at the molecular level. In addition, the programme will support about 150 long- and short-term fellowships and 10 workshops for research in these fields.

Conditions for the grant applications are similar to those for a 'pilot' programme launched last year, except that the research teams do not need to include Japanese. The pilot programme has come under some criticism from Western scientists whose applications failed because they received no explanation for failure (Nature 340, 494; 1989).

The guidebook for this year's grant applications retains a clause stating that "the review process will be confidential; no explanation , therefore, will be offered and no correspondence can be entered into on decisions taken". But Toichi Sakata, director of Frontiers at the Science and Technology Agency, says that once the Frontiers foundation is established in Strasbourg next month, the Frontiers science council and/or grant review committees can alter this rule if they think appropriate.

Last week, the agency and the Ministry of International Trade and Industry (MITI) applied for a total of $¥ 3,307$ million ( $\$ 23$ million) for Frontiers in 1990. And with the increased budget and some support from other nations, Sakata hopes the number of grants will increase to "about 26 or 27 " in 1990.

\section{INSERM's man speaks out}

\section{Paris}

IN a book due to be published shortly, the director-general of the French national institute of health and medical research (INSERM), Philippe Lazar, suggests that major journals inadvertently run the risk of discouraging originality in research. In a chapter entitled 'Avatars of originality', Lazar criticizes Nature over its reactions to the controversial paper by Jacques Benveniste on the molecular 'memory of water' (see Nature 340, 178; 1989).

In his book, which gives the reader an 'inside view' of the preoccupations of the director of a national medical research organization, Lazar defends INSERM's practice of four-yearly laboratory reviews by an elected committee of experts. The system, he says, should maximize the emergence of "truly innovative work" because, for laboratories wholly funded by INSERM, the reviews are retrospective. But, says Lazar, research which is "off the beaten track" stands little chance of being published quickly, both because it is usually unproductive at first and because major journals may be reluctant to publish it. And publication is often a criterion of merit when assessing grant proposals.

By publishing Benveniste's paper on condition that the experiments be repeated in the presence of a panel sent by Nature, Lazar says that the journal cast itself in the role of scientific "establishment". $\mathrm{He}$ wonders whether Nature's editors "had a real moment of difficulty at the idea of challenging, in their own right ..." an example of "truly original research".

Nature, he adds, should have left it to the scientific community "to play its fundamental role of filter at its own pace". Any other procedure, he says, is "dangerous" and evokes "the spectre of 'official' science".

These are substantially the criticisms made by Lazar at a press conference last month at which it was announced that Benveniste's tenure had been renewed until the end of the year.

Lazar also attacks the press for what he considers an excessive zeal during the height of the affair.

To counterbalance the weight accorded by grant review committees to publication in major journals - and the consequent influence of conservative peer reviewers on the kinds of research supported Lazar wants to offer a series of small grants for 'high risk' innovative research. He says he is not convinced the idea will work, but adds that he would "regret having to renounce the idea for want of support".

Peter Coles

Les Explorateurs de la Santé is published by Editions Odile Jacob, Paris, Iater this year. 